\title{
FORMAÇÃO PEDAGÓGICA DO TECNÓLOGO PARA ATUAÇÃO COMO DOCENTE NO INSTITUTO FEDERAL DO AMAPÁ - CAMPUS MACAPÁ
}

\author{
E. P. SOUSA ${ }^{1}$, A. L. SALES', J. D. P. SILVA ${ }^{3}$, D. M. LEMOS ${ }^{4}$, E. T. S. S. FRANÇA ${ }^{5}$
}

Instituto Federal de Educação, Ciência e Tecnologia do Amapá1,2,3, Instituto Federal de Educação, Ciência e Tecnologia de Alagoas ${ }^{4}$, Instituto Federal de Educação, Ciência e Tecnologia do Maranhão ${ }^{5}$ elisabete_pianco@yahoo.com.br ${ }^{1}$

Artigo submetido 05/02/2018 e aceito 24/06/2019

DOI: $10.15628 /$ holos.2019.6899

\section{RESUMO}

O docente que possui qualquer formação inicial que não seja a licenciatura necessita de uma complementação pedagógica para atuar na docência. Para isso, nos últimos anos os IFs vêm buscando implantar cursos de formação pedagógica, haja vista habilitar e capacitar os docentes que ainda não possuem tal formação. Nesse estudo objetivou-se avaliar a importância da formação pedagógica do tecnólogo para atuação como docente no Instituto Federal do Amapá - Campus Macapá. A pesquisa de campo foi realizada durante o ano letivo de 2017, sendo necessárias as seguintes etapas: análise documental (perfil para participar da pesquisa), aplicação dos questionários a todos os professores com a formação de tecnólogo, totalizando doze professores, sendo que apenas 9 responderam o questionário. Por meio do questionário foi possível traçar o perfil do docente, no que se refere a sexo, faixa etária, regime de trabalho, formação, experiência profissional (no magistério e em outras atividades), as especificidades e os desafios da prática docente na Educação Profissinal e Tecnólogica
(EPT), conforme em estudos realizado por Silva (2003) e Pena (2014) ). Todavia, todo e qualquer docente deve atender ao processo de ensino / aprendizagem, sendo que antes devem ter conhecimento das diversidades e modalidades de ensino, situações e contexto social em que os discentes vivem, de modo que atendam aos anseios da sociedade como um todo. Os docentes que participaram dessa pesquisa salientaram que os cursos de formação continuada contribuem consideravelmente para a formação do tecnólogo, tendo em vista que é de suma importância para prática docente no sentido de aprimoramento de métodos de avaliações, aulas inovadoras, construção de provas contextualizadas, conhecer novas perspectivas sobre o ensino e regulamentações voltadas para atuação docente. $\mathrm{Na}$ dinâmica ensino / aprendizagem os docentes necessitam de capacitação para atender de forma satisfatória as diferentes modalidades de ensino e diversidade de cursos ofertados pela Instituição.

\section{PALAVRAS-CHAVE: Educação Profissional e Tecnológica, formação continuada, saberes docente. \\ PEDAGOGICAL TRAINING OF THE TECHNOLOGIST TO ACT AS A TEACHER IN THE FAPTER INSTITUTE OF AMAPÁ - CAMPUS MACAPÁ}

\section{ABSTRACT}

The teacher who has any initial training other than the degree requires a pedagogical complementation to act in teaching. In order to do this, in recent years Fls have been seeking to implement pedagogical training courses, with a view to enabling and qualifying teachers who do not yet have such training. This study aimed to evaluate the importance of the pedagogical training of the technologist for teaching at the Federal Institute of Amapá - Campus Macapá. Field research was carried out during the 2017 school year, with the following steps: documentary analysis (profile to participate in the research), application of questionnaires to all teachers with the training of technologist, totaling twelve teachers, with only 9 answered the questionnaire. Through the questionnaire it was possible to trace the profile of the teacher, regarding gender, age, work regime, training, professional experience (in teaching and other activities), the specificities and challenges of teaching practice in Professional Education and Technological (EPT) according to studies done by Silva (2003) and Pena (2014). However, every teacher must attend to the teaching / learning process, but must first be aware of the diversity and modalities of teaching, situations and social context in which the students live, so that they meet the wishes of society as a whole. Teachers who participated in this research emphasized that continuing education courses contribute considerably to the training of the technologist, since it is of paramount importance for teaching practice in the sense of improving methods of evaluation, innovative classes, construction of contextualized tests, knowing new perspectives on teaching and regulations aimed at teaching. In the teaching / learning dynamic, teachers need the training to satisfactorily attend to the different teaching modalities and diversity of courses offered by the Institution. 


\section{INTRODUÇÃO}

O Ensino constitui uma dimensão muito ampla, pois compreende um conjunto de desafios que exige dos professores saberes diversos relacionados à docência que, minimamente, perpassam pelo domínio de conteúdos específicos da área de atuação, metodologias diferenciadas para a transposição didática dos conteúdos, tendo em vista que os mesmos devem conhecer um pouco das diferentes áreas do conhecimento que fazem parte da matriz curricular dos discentes. Da mesma forma, devem estar sintonizados com as tendências do mundo do trabalho, acompanhar os avanços científicos e tecnológicos da sua área de formação, como das áreas que possa vir atuar como docente na Instituição (Aguiar, 2016).

Conforme a Lei no 11.892, de 29 de dezembro de 2008 (Brasil, 2008), que "institui a Rede Federal de Educação Profissional, Científica e Tecnológica, cria os Institutos Federais de Educação, Ciência e Tecnologia e dá outras providências", em seu Art. 6으, inciso I, os Institutos Federais de Educação, Ciência e Tecnologia (IFs) visam "ofertar uma educação profissional e tecnológica em todos os seus níveis e modalidades, formando e qualificando cidadãos com vistas à atuação profissional nos diversos setores da economia, com ênfase no desenvolvimento socioeconômico local, regional e nacional".

A educação profissional foi ampliada com as implantação do IFs e com isso maior atuação de docentes sem nenhuma formação pedagógica, somente com a experiência prática, sendo que professores com formação em bacharelado, engenharia, tecnólogo, necessitam de uma complementação pedagógica, muitas vezes presente sucintamente na legislação vigente mais não cumprida pela maioria das instituições de ensino da educação profissional tecnológica (Cunha, 2006).

Em se tratando dos diferentes cursos de Tecnologia, os mesmos têm se expandido nesses últimos anos, principalmente devido ao crescimento populacional, a necessidade de expansão e a tendência mercadológica. Nesse contexto, já é possível encontrar inúmeros profissionais com tal formação, exercendo a docência, sendo importante a apropriação de conhecimentos e habilidades referentes às práticas pedagógicas.

Com intuito de mudar essa realidade, nos últimos anos os IFs vêm buscando implantar cursos de formação pedagógica, haja vista habilitar e capacitar os docentes que ainda não possuem tal formação. Dessa forma, o referido estudo objetivou-se avaliar a importância da formação pedagógica do tecnólogo para atuação como docente no Instituto Federal do Amapá - Campus Macapá. 


\section{REVISÃO BIBLIOGRÁFICA}

\section{Formação do Tecnólogo}

Desde os anos 90 a formação do tecnólogo vem sendo amplamente difundida no Brasil a tanto no setor público quanto privado, sendo os cursos ministrados em Instituições de Ensino Superior (IES) ou Instituto Federal de Educação Tecnológica (IFET).

O Ministério da Educação afirma que os cursos tecnólogos deve:

Qualificar profissionais em cursos superiores de educação tecnológica para os diversos setores da economia e realizar pesquisa e desenvolvimento tecnológico de novos processos, produtos e serviços, em estreita articulação com os setores produtivos e a sociedade, oferecendo, inclusive, mecanismos para a educação continuada (Lordelo, 2011, p. 19).

O Ministério da Educação publicou, em dezembro de 2006, a primeira versão do Catálogo Nacional de Cursos Superiores de Tecnologia, o qual considera as Diretrizes Curriculares Nacionais para a Educação Profissional de Nível Tecnológico e está "em sintonia com a dinâmica do setor produtivo e os requerimentos da sociedade" (Brasil, 2010).

Consoante Barbosa (2009), os cursos tecnólogos priorizam os processos típicos de cada área profissional e são voltados para a conciliação entre teoria e prática com o intuito de proporcionar ao estudante o aprimoramento de habilidades e competências específicas em um tempo médio relativamente menor se comparado à aqueles praticados pelos cursos de graduação tradicionais. Assim,

[...] a formação de tecnólogos para a carreira docente, realidade crescente nos diferentes Centros de Formação Profissional, aponta-se que é possível e necessário que se adotem e se intensifiquem políticas no sentido de: a) Articulação Interinstitucional, com o apoio e incremento governamental para a Instituição de programas de formação continuada no sentido da instalação de cursos de extensão, Pós-Graduação e Pesquisa; b) Instituição de Núcleos de estudos de Pesquisa em Educação e Trabalho nos Centros Federais de Educação Tecnológica c) Capacitação dos professores no seu conteúdo técnico de sua área/disciplina. As mudanças na educação por melhor que sejam concebidas estarão sempre condicionadas ao engajamento e compromisso do professor em rever permanentemente a sua prática. (Pereira, 2004, p. 14-15).

\section{Atuação docente na educação profissional e tecnológica}

Os Institutos Federais de Educação, Ciência e Tecnologia são especializados na oferta de educação profissional e tecnológica, e considerados como instituições de educação superior, básica e profissional. Neste contexto, a diversificação de níveis de ensino ofertados, no âmbito de seu histórico caracterizado pela formação de educação técnica profissional, demonstra que os Institutos Federais consistem em um locus distinto, se comparados às demais instituições de ensino brasileiras (Lima, 2014). 
Diante da diversidade de níveis e modalidades de ensino ofertado nos Institutos Federais, os profissionais da educação em atuação nesse espaço, particularmente os docentes, precisam desenvolver práticas educativas capazes de articular educação, ciência, tecnologia e cultura, assentados no tripé ensino, pesquisa e extensão.

Os conhecimentos que o docente deve possuir para atuar nos Institutos são saberes técnicos relacionados a sua área de conhecimento, saberes pedagógicos ligados à educação e ao processo de ensino e de aprendizagem, bem como saberes da experiência adquiridos ao longo da sua trajetória pessoal e profissional nos diversos espaços sociais.

De acordo com Pacheco (2008), a formação dos docentes deve contemplar alguns objetivos: dinamização da relação ensino-aprendizagem mediante a contextualização dos conhecimentos, comprometimento com a educação inclusiva, reconhecimento dos discentes de que o processo formativo é voltado para indivíduos que possuem diferenças e expectativas, desenvolvimento de práticas pedagógicas que busquem a integração entre áreas de conhecimento, utilização das novas tecnologias no processo de ensino-aprendizagem, comprometimento com a ética profissional, valorização do trabalho coletivo por meio de ação crítica e cooperativa na construção do conhecimento.

O professor e o ensino constituem objetos de saber para as ciências da educação. Nessa perspectiva, esses conhecimentos tornam os saberes destinados à formação científica ou erudita dos professores, e caso seja incorporado à prática docente, esta pode transformar-se em prática cientifica (Tardif, 2002).

Desse modo, a articulação e reconstrução desses diversos saberes permitem aos docentes a constante transformação de suas práticas, posturas e conhecimento, os quais são fundamentais na sua atuação profissional.

\section{Desenvolvimento de suas práticas pedagógica}

A prática pedagógica é considerada para além da execução de uma tarefa por parte do professor, dentro da escola, ou da sala de aula. Uma prática pedagógica consiste em um processo complexo que implica o desenvolvimento de uma atitude que leve a produção do conhecimento e o envolvimento de toda comunidade escolar (Camargo \& Poloni, 2007).

Para realização das práticas pedagógicas existem necessidade de formar professores que aprendam a pensar, a correlacionar teoria e prática, a buscar, de modo criativo e adequado às necessidades da sociedade, a resolução dos problemas que emergem no dia-a-dia da escola e no cotidiano. "Professores aptos a agregar para si transformações em suas práticas, já que o método tradicional tem se mostrado ineficaz e ineficiente em função das exigências da realidade social, da urgência em ampliar o acesso escolar e cultural da classe menos favorecida dado o avanço tecnológico e científico “(Gemignani, 2012,p.12). 
O perfil profissional do docente da educação profissional engloba, além das especificidades das atividades pedagógicas relativas ao processo de ensino-aprendizagem, as dimensões próprias do planejamento, organização, gestão e avaliação desta modalidade educacional nas suas íntimas relações com as esferas da educação básica e superior (Machado, 2008).

\section{METODOLOGIA}

O referido estudo teve como proposta a aplicação de questionário para os docentes que têm na sua formação Curso de Tecnologia, com o intuito de avaliar a formação pedagógica do tecnólogo para atuação docente no Instituto Federal do Amapá (IFAP) - Campus Macapá.

O lócus da pesquisa foi o IFAP - Campus Macapá. A implantação do Instituto Federal do Amapá ocorreu em 2008, uma instituição de educação superior, básica e profissional, plurricurricular, multicampi e descentralizada. A partir de 2010, seguindo a política de atuação da Rede Federal de Educação Profissional e Tecnológica, o IFAP passa a ofertar gradativamente cursos nos diferentes níveis e modalidades do ensino técnico e tecnológico, com o compromisso de viabilizar o desenvolvimento integral do cidadão trabalhador. O campus Macapá foi selecionado para a realização da pesquisa em virtude de possuir Cursos Superiores de Tecnologia, dentre eles: Tecnologia em Alimentos, Tecnologia em Construção de Edifícios e Tecnologia em redes de computadores.

Para a realização desse trabalho, fez-se um levantamento bibliográfico sobre o tema em estudo, os sujeitos envolvidos foram os docentes com formação tecnológica. O questionário foi elaborado com com perguntas de múltiplas escolha e discursivas no google drive com intuito de facilitar a coleta e tratamento de dados. Para Silva (2003), o questionário é uma forma de coletar informações sobre determinada pesquisa e que facilita a coleta destes. Pois o próprio informante preenche.

A pesquisa de campo foi realizada durante o ano letivo de 2017, sendo necessárias as seguintes etapas: análise documental (perfil para participar da pesquisa), aplicação dos questionários a todos os professores como formação de tecnólogo, totalizando doze professores, sendo que apenas 9 responderam o questionário. Por meio do questionário foi possível traçar o perfil do docente, no que se refere a sexo, faixa etária, regime de trabalho, formação, experiência profissional (no magistério e em outras atividades), as especificidades e os desafios da prática docente na Educação ProfissinalTecnólogica (EPT). Este visa realizar uma pesquisa quantitativa conforme a metodologia de Pena (2014) e algumas adaptações.

O presente trabalho adotou abordagem quantitativas. Ponte et al. (2012), ambas são utilizadas com frequência em diversos estudos e cada uma possui suas peculiaridades e tem sua importância de acordo com o problema a ser investigado. Nas quantitativas, podem ser usados diferentes tipos de estudo, assim como instrumentos de coleta de dados e de análise de dados. 


\section{RESULTADOS E DISCUSSÕES}

Nos dias atuais, percebe-se que a formação tecnológica tem se expandido e que os docentes que possuem tal formação buscam atender às diversas modalidades de ensino ofertadas pela Rede IF, na qual é uma das instituições de ensino que mais oferta curso de Tecnologia. De acordo com Araújo (2008), o curso de tecnologia confere o diploma de tecnólogo e está voltado para uma formação mais dinâmica e prática, e que propõe profundidade, conhecimento focado e contextualizado, autonomia e educação continuada.

No referido estudo foram envolvidos docentes com formação em tecnologia do campus Macapá que possuíam uma faixa etária entre 30 a 41 anos de idade. Na Figura 1 tem-se a relação da quantidade dos docentes envolvidos na pesquisa e o tempo de docência. Foi constatado que os docentes apresentam tempo de docência entre um ano a sete anos. Para Fonseca (2017), cada docente possui peculiaridades na formação e na atuação docente.

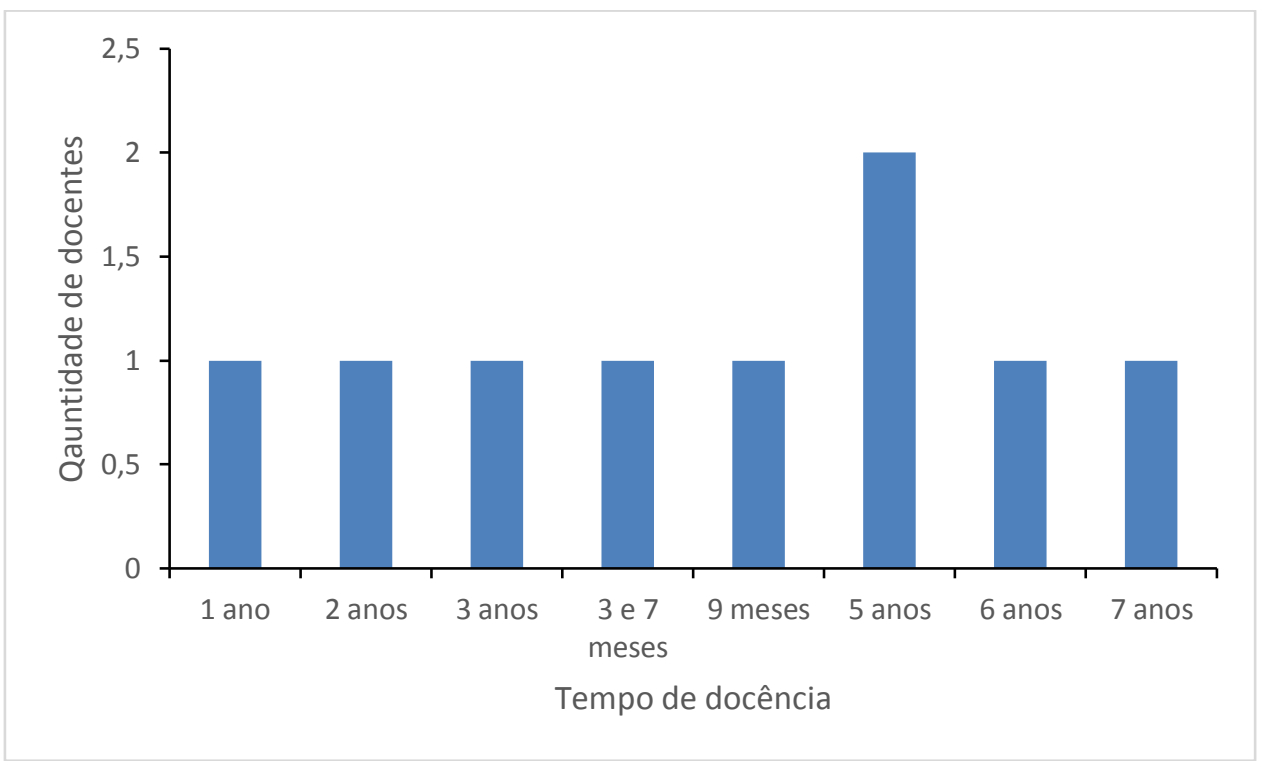

Figura 1- Relação da quantidade de docentes tecnólogos no campus Macapá $X$ tempo de docência

Conforme os dados da Figura 2, dos docentes envolvidos nessa pesquisa, 5 (cinco) mestre e possuem um regime de trabalho de 40 horas e dedicação exclusiva, 3 como formação docente especialização e regime de trabalho 40 horas, no entanto nota-se que a maioria possui como maior nível de escolaridade o mestrado e 40 horas e dedicação exclusiva. Moura (2013) define a formação dos docentes em dois eixos: um refere-se à área específica do conhecimento que é a graduação (formação inicial), e em outros níveis mais elevados de ensino (mestrado e doutorado) que estes são capazes de refletir na formação didático-político pedagógica. Henrique e Cavalcante (2016) cada um desses eixos apresenta necessidades diferenciadas em relação à formação para atuar como docente da EPT (Educação Profissional e Tecnológica). 


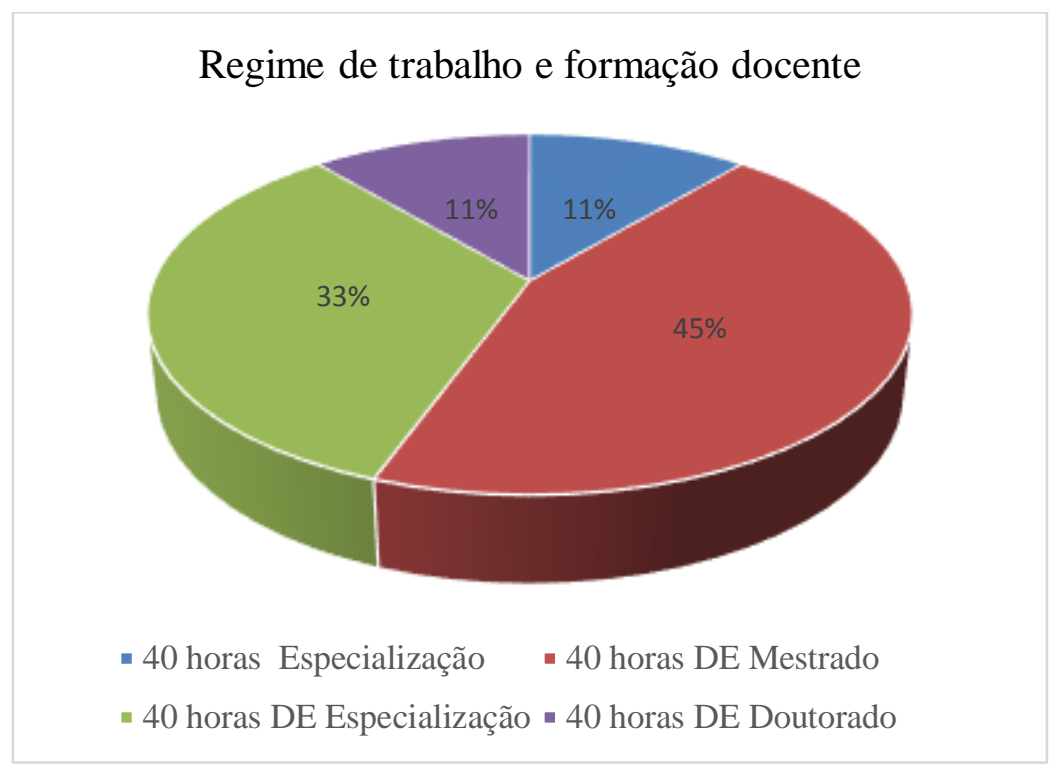

Figura 2- Regime de trabalho e formação docente

Os docentes envolvidos nesta pesquisa atuam lecionando disciplinas para cursos de nível técnico, graduação e pós-graduação, sendo que a maior atuação foi nos cursos de nível médio e graduação. Estes lecionam em diferentes turnos (manhã, tarde e noite). De acordo com os resultados do questionário os docentes já haviam ensinado em outras Instituições antes de trabalhar no IFAP, sendo que nenhum atuou em escola da rede municipal.

De acordo com a Figura 3, tem-se que 66,7 \% dos docentes atuaram em escola na rede federal (médio, técnico e tecnológico), 33,3\% em escola na rede privada e 33,3\% em escola na rede privada. Paiva, Correia e Batista (2017) dizem que os docentes (tecnólogos), muitas vezes têm sua primeira atuação profissional no magistério sem, no entanto, terem contato com os saberes pedagógicos necessários à atuação docente e/ou com as diversas modalidade de ensino durante sua formação acadêmica.

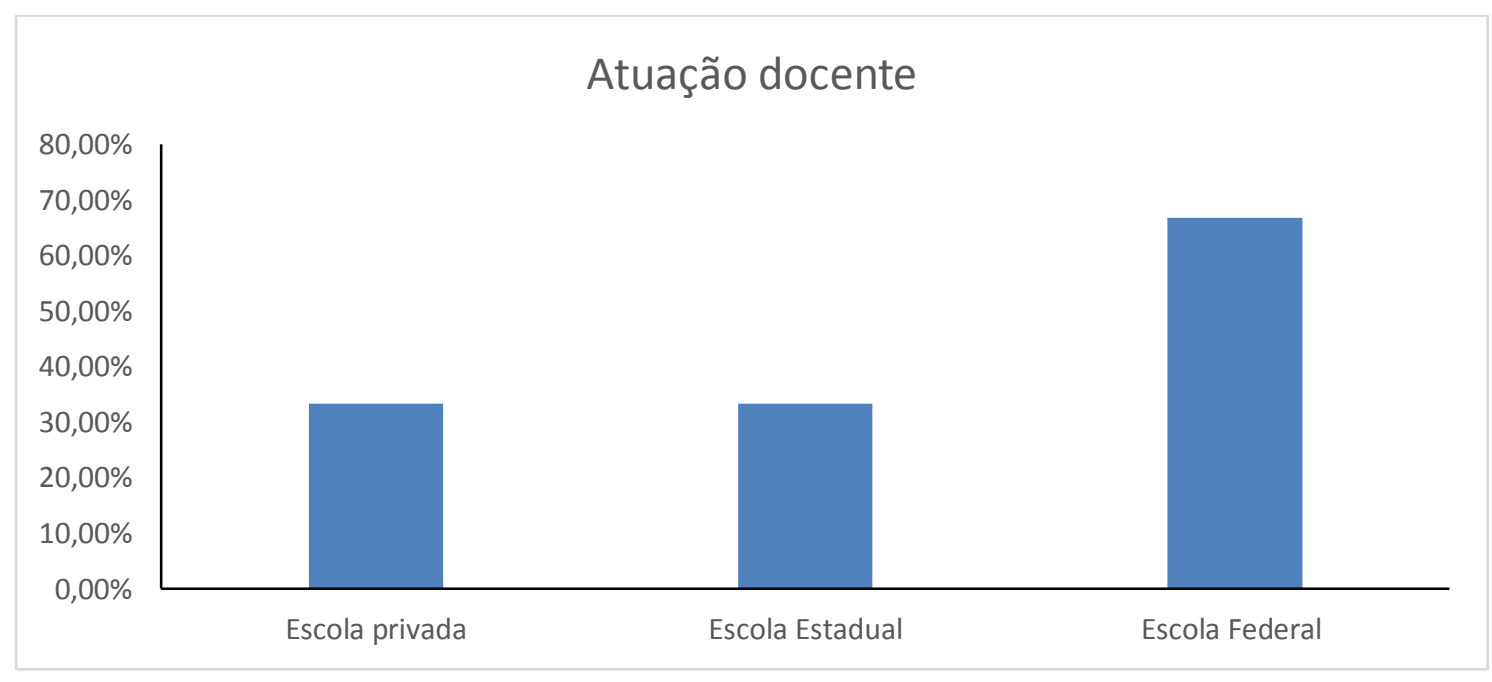

Figura 3- Atuação docente 
A Figura 4, apresenta o percentual de docentes que receberam instruções para iniciarem as atividades docentes, nota-se apenas $30 \%$ dos docentes que responderam o questionário não receberam instruções. Os demais docentes recebam instruções voltadas para assiduidade, planos de aulas e ensinos. Estas são instruções básicas as quais o setor pedagógico necessita para comprovar as atividades voltadas para ensino e que o docente tem como norte para saber o que deve ministrar em sala.

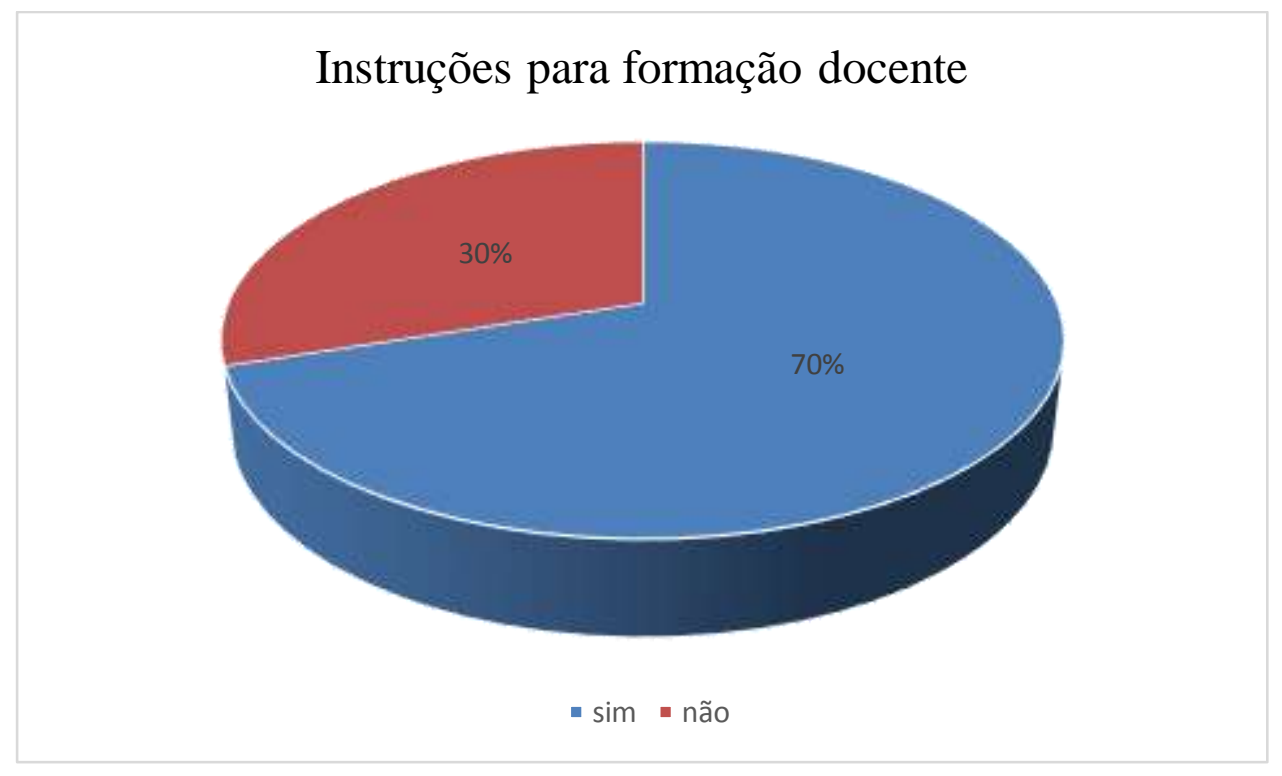

Figura 4: Instruções para início das atividades docentes

Todavia, todo e qualquer docente deve atender ao processo de ensino / aprendizagem, sendo que antes deve ter conhecimento das diversas modalidades de ensino, situações e contexto social que os discentes vivem, de modo que atenda os anseios da sociedade como um todo. Freitas et al (2016) afirmam que no processo ensino-aprendizagem, além de possuir conhecimentos básicos da área de atuação profissional, o docente deve possuir o domínio pedagógico para exercer a docência.

Todavia, para atuação na educação profissional e tecnológica, os docentes devem receber instruções como: conhecer o funcionamento do campus, trâmite de documentação, hierarquia dos setores ou departamentos e função dos indivíduos dos respectivos servidores, atividades que fazem parte da pesquisa e extensão, atividades voltadas para o ensino - sistema de avaliação de acordo com a modalidade de ensino, grau de dificuldade dos discentes, programas (monitoria), participação de capacitação didático-pedagógica a fim de melhor ministrarem suas aulas. Para isso, é necessário que a Instituição (IFAP Campus Macapá) trabalhe os conceitos relacionados à educação, ensino e aprendizagem, desenvolva as diretrizes de organização do ensino, calcadas nas tendências pedagógicas, focalizando o planejamento, a seleção dos conteúdos, das técnicas, dos recursos didáticos, dos instrumentos avaliativos.

No referido estudo constatou-se que $55,6 \%$ dos docentes realizaram cursos de formação continuada nos últimos 12 meses. Na tabela 1, tem-se os resultados dos cursos de formação continuada que os docentes julgaram relevantes para atuação como docentes. 
Quadro 1- Curso de formação continuada relevantes para prática docente

\begin{tabular}{|c|c|}
\hline Docente & $\begin{array}{c}\text { Curso de formação para prática } \\
\text { docente }\end{array}$ \\
\hline A & Ensino baseado em projetos \\
\hline B & Curso de autocad \\
\hline C & Doutorado \\
\hline D & Práticas pedagógicas contemporâneas \\
\hline E & $\begin{array}{c}\text { Meio ambiente, segurança do trabalho, } \\
\text { tratamento de minérios }\end{array}$ \\
\hline F & Metodologia de pesquisa \\
\hline$G$ & $\begin{array}{c}\text { Formação docente para cursos de tecnologias, } \\
\text { conhecendo regimentos para docentes EBTT, } \\
\text { inclusão e diversidade no IFs }\end{array}$ \\
\hline $\mathrm{H}$ & $\begin{array}{c}\text { Curso na área de pedagogia e na área de } \\
\text { humanas }\end{array}$ \\
\hline & \\
\hline
\end{tabular}

Os docentes mencionaram curso de formação continuada direcionado para sua área de formação, pois cada um possui uma necessidade específica, sedo que para realização destes é necessário apoio dos gestores. Brasil (2015), "formação continuada é processo dinâmico e complexo, direcionado à melhoria permanente da qualidade social da educação e à valorização profissional, devendo ser assumida em regime de colaboração pelos entes federados nos respectivos sistemas de ensino e desenvolvida pelas instituições de educação, tendo em vista manter um padrão de qualidade acadêmica na formação oferecida".

Nesse estudo foram mencionadas algumas dificuldades para realizar a prática docente: falta de recursos didáticos, quantidade de conteúdo a ser ministrado em relação ao tempo de aula, dinâmica dos assuntos a serem trabalhados, dinâmica de trabalho da instituição e interação do aluno e professor. Essas dificuldades podem estar relacionadas a quantidade de cursos ofertados pelo campus Macapá, elaboração dos planos de cursos que consequentemente influenciam em um ensino deficitário no momento da realização. De acordo com esse estudo foi evidenciado que dos tecnólogos entrevistados 22,2\% não apresentam dificuldades na dinâmica ensino/aprendizagem. Vieira, Vieira e Pasqualli (2014) afirmam que o processo de formação continuada deveria iniciar ainda na formação inicial, sendo os docentes responsáveis por incentivar a busca da formação pedagógica dos futuros tecnólogos, para que os mesmos possam atender às necessidades da atualidade, pois poderão atuar em indústrias ou em instituições de ensino. Para atuação como 
docente são necessárias habilidades didático-pedagógicas, conhecimentos teóricos e práticos que demandam modos específicos de aprendizagem.

Os docentes que participaram dessa pesquisa salientaram que os cursos de formação continuada contribuem consideravelmente para formação do tecnólogo, tendo em vista que é de suma importância para a prática docente no sentido de aprimoramento de métodos de avaliações, aulas inovadoras, construção de provas textualizadas, conhecer novas perspectivas sobre o ensino e regulamentações do voltadas para o ensino, de modo que facilite a dinâmica ensino e aprendizagem para melhor atender a diversidade de alunos, cursos e modalidades de ensino.

\section{CONCLUSÃO}

A maioria dos tecnólogos que atuam no Instituto Federal do Amapá, campus Macapá que participaram desse estudo receberam instruções para realizar sua prática docente no início das atividades e afirmaram que para realização desta é necessário constantemente cursos de formação continuada. Este trabalho de pesquisa produziu reflexões críticas e/ou confirmou a necessidade de conhecimentos para o desenvolvimento do processo de formação pedagógica de docentes da educação profissional.

Na dinâmica ensino / aprendizagem os docentes necessitam de capacitação para atender de forma satisfatória as diferentes modalidades de ensino e diversidade de cursos ofertados pela Instituição. Esta oferta de formação ocorre conforme as necessidades que surgem de acordo com admissão de docentes ( tecnólogos e bachareis) que precisam de formação pedagógica para melhor exercer docência.

\section{REFERÊNCIAS BIBLIOGRÁFICAS}

Aguiar, R. F. (2016). Docência na educação profissional e tecnológica: influência da formação no processo ensino-aprendizagem. Dissertação de mestrado, Universidade de Brasília, Brasilia, DF, Brasil.

Araujo, A. B. (2008). Educação tecnológica para a indústria brasileira. Revista Brasileira da Educação Profissional e Tecnológica, 1( 1), 80-84.

Barbosa, M. L. de O.(2009). Estudo sobre o campo de atuação do tecnólogo. (Série Estudos Educacionais, n. 5). Brasília: SENAI/DN.

Resolução CNE/CP no 2, de 1o de julho de 2015. Define as Diretrizes Curriculares Nacionais para a formação inicial em nível superior (cursos de licenciatura, cursos de formação pedagógica para graduados e cursos de segunda licenciatura) e para a formação continuada. Disponível em: $<$ http://portal.mec.gov.br/conselho-nacional-de-educacao/atos-normativos--sumulaspareceres-e-resolucoes?id=21028>. Acesso em: 20 jan. 2018. 
Lein. 11.892, de 29 de dezembro de 2008. Institui a Rede Federal de Educação Profissional, Científica e Tecnológica. Brasília, DF, 2008. Disponível em: <http://www.planalto.gov.br/ccivil_03/_ato2007-2010/2008/lei//11892.htm>. Acesso em: 18 nov. 2017.

Catálogo nacional de cursos superiores de tecnologia. Brasília: Ministério da Educação, 2010.

Camargo, I. B., \& POLONI, F. A. (2007). A prática pedagógica apoiada pelas tecnologias no ensino técnico. VII Congresso Nacional de Educação (EDUCERE) - Edição Internacional: "Saberes Docentes". São Paulo, 6.

Cunha, M. I. (2006). Docência na universidade, cultura e avaliação institucional: saberes silenciados em questão. Revista Brasileira de Educação, 11 (32), 258- 271.

Fonseca, C. M. F. (2017).Formação e saberes docentes na educação profissional: um relato de experiência. Revista brasileira da educação profissional tecnológica, 1 (12), 170-178.

Freitas, D. A., Santos, E. M. S., Lima, L. V. S., Miranda, L. N., Vasconcelos, E. L., \& Nagliate, P. C.(2016). Saberes docentes sobre processo ensino-aprendizagem e sua importância para a formação profissional em saúde. Revista comunicação saúde educação, 20 (57), 437-48.

Gemignani, E. Y M. (2012). Formação de professores e metodologias ativas de ensino aprendizagem: ensinar para a compreensão. Fronteiras da Educação,1, (2) , 1-27.

Henrique, A. L. S., \& Cavalcante, I. F. (2016). Formação docente para a educação profissional: relato de uma experiência de pesquisa. Anais do III Colóquio Nacional. Natal, Rio Grande do Norte,3.

Lima, F. B. G. (2014). A formação de professores nos institutos federais de educação, ciência e tecnologia: um estudo da concepção política. Natal: Editora do IFRN.

Lordelo, S. N. B. (2011). Mundo do trabalho e a formação do tecnólogo: compreensões necessárias à construção da sua identidade profissional.Tese de Doutorado, Faculdade de Educação Universidade Federal da Bahia, Salvador, BA, Brasil.

Machado, L. R. S.(2008). Diferenciais inovadores na formação de professores para a educação profissional. Revista Brasileira da Educação Profissional e Tecnológica, 1( 1), 25-39.

Moura, D. H. (2013). Produção do conhecimento, políticas públicas e formação docente em educação profissional. São Paulo: Mercado das letras.

Pacheco,E.M.(2008). Bases para uma Política Nacional de EPT. Disponível em: < http://portal.mec.gov.br/setec/arquivos/pdf2/artigos bases.pdf> . Acesso em: 30 maio 2017.

Paiva, S. Y., Correia, D. B. de B., \& Batista, A. C.(2017). Perfil de formação de professores da educação profissional que atuam em instituições privadas no RN: uma análise a partir das vozes dos docentes do eixo geral. Revista brasileira da educação profissional tecnológica, 1(12), 157-169. 
Pena, G. A. C. (2014). Docência na educação profissional e tecnológica: conhecimentos, práticas e desafios de professores de cursos técnicos na rede Federal. Tese de doutorado, Faculdade de Educação da Universidade Federal de Minas Gerais, Belo Horizonte,MG, Brasil.

Pereira, L. A. C.(2004). A formação de professores para a educação profissional. Fórum de educação profissional. Brasília-DF.

Ponte, K. M. de A.; Borges, M. C. L. A.; Barreto, F. A.; Moreira, T. M. M.; SILVA, L. de F. da; FIALHO, A. V. de M. (2012). Produção científica em enfermagem cirúrgica: análise dos estudos quantitativos. Revista Rene, 13 (1), 231-41.

Silva, M. A.F. (2003). Métodos e técnica de pesquisa. 2. ed. Curitiba: Ibpex.

Tardif, M. (2002). Saberes docentes e formação profissional. Petrópolis: Editora Vozes.

Vieira, M. M. M.; Vieira, J. A.; Pasqualli, R.(2014). Formação de professores da educação profissional nos programas especiais de formação pedagógica. Revista brasileira da educação profissional tecnológica, 1 (7), 43-55. 